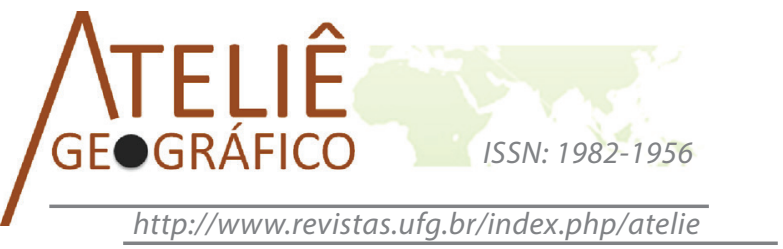

\section{Territorialidades ribeirinhas: habitus, ethos ambiental e sustentabilidade no lago do Zé Açu/Parintins-Am}

\author{
Riparian Territorialities: habitus, environmental ethos, and \\ sustainability in the Zé Açu lake, Parintins, AM
}

\section{Territorialidades ribereñas: habitus, ethos ambiental y sustentabilidad en el lago Zé Açu/Parintins-Am.}

\author{
Charlene Maria Muniz da Silva \\ Universidade do Estado do Amazonas \\ charlenemds@yahoo.com.br
}

\author{
Therezinha de Jesus Pinto Fraxe \\ Universidade Federal do Amazonas \\ tecafraxe@uol.com.br
}

\begin{abstract}
Resumo
Este artigo buscou compreender as territorialidades rurais no município de Parintins/ AM e sua relação com a sustentabilidade socioambiental, a partir da análise do habitus e o ethos ambiental na localidade do Zé Açu. Realizou-se um survey com aplicação de formulários, observação participante, entrevistas individuais e coletivas (grupo focal). É pela agricultura e a pesca que são repassados os conhecimentos tradicionais, onde a terra e a água tornam-se o lócus da reprodução da vida das famílias ribeirinhas do Zé Açu. Os principais problemas ambientais na detectados foram: o assoreamento do lago, desmatamento para a pecuária, extração mineral e o aumento na produção de resíduos sólidos com destinação inadequada. Há pouca presença de órgãos ambientais e institutos de pesquisa para que se possam evitar/mitigar esses problemas que já afetam os modos de vida dos ribeirinhos. A compreensão da relação do território com a cultura, aqui apresentada pode auxiliar nas reflexões sobre as estratégias utilizadas por esses grupos para ordenar e controlar melhor seus territórios.
\end{abstract}

Palavras-Chave: Territorialidades; Sustentabilidade; Habitus; Ethos Ambiental. 


\begin{abstract}
This article seeks to understand the rural territoriality in the municipality of Parintins, in the state of Amazonas, and its relation to socio-environmental sustainability through an analysis of the habitus and environmental ethos in the locale of Zé Açu. A survey was carried out with the application of questionnaires, participant observations, and individual and group (focus group) interviews. Traditional knowledge is passed down through agriculture and fishing, where the land and the water become the locus for the reproduction of life by the riparian families of Zé Açu. The main environmental problems detected there were: the silting up of the lake, deforestation for ranching, mineral extraction, and the increased production of solid waste with improper disposal. There is little presence of environmental agencies and research institutes that could avoid/mitigate these problems, which are already affecting the river-dwellers' way of life. An understanding of the relationship between territory and culture presented herein can aid in reflections about the strategies used by these groups to better organize and control their territories.
\end{abstract}

Keywords: Territorialities; Sustainability; Habitus; Environmental Ethos.

\begin{abstract}
Resumen
Este artículo buscó comprender las territorialidades rurales en el municipio de Parintins/AM y su relación con la sustentabilidad socioambiental, a partir del análisis del habitus y el ethos ambiental en la localidad de Zé Açu. Se realizó un survey con aplicación de formularios, observación participante, entrevistas individuales y colectivas (grupo focal). Es a través de la agricultura y de la pesca que son repasados los conocimientos tradicionales, en donde la tierra y el agua se transforman en el locus de la reproducción de la vida de las familias ribereñas de Zé Açu. Los principales problemas ambientales detectados fueron: la sedimentación en el lago, deforestación para la ganadería, extracción mineral y el aumento en la producción de residuos sólidos con destino inadecuado. Hay poca presencia de órganos ambientales e institutos de investigación para que se puedan evitar/mitigar esos problemas que ya afectan los modos de vida de los ribereños. La comprensión de la relación del territorio con la cultura aquí presentada puede ayudar en las reflexiones sobre las estrategias utilizadas por esos grupos para ordenar y controlar mejor sus territorios.
\end{abstract}

Palabras clave: Territorialidades; Sustentabilidad; Habitus; Ethos Ambiental.

\title{
Introdução
}

A pesquisa buscou compreender as territorialidades dos ribeirinhos do lago do Zé Açu, município de Parintins/AM, e a sua relação com a sustentabilidade socioambiental, a partir da análise de seu habitus e o ethos ambiental.

As categorias analíticas território, lugar, habitus e ethos contribuíram na compreensão dessas territorialidades. Autores como Haesbaert (2009), Saquet (2009), Fraxe (2004) e Bourdieu (1979) ajudaram a pensar essas categorias, fazendo a interrelação com a questão da sustentabilidade dos territórios ribeirinhos.

O território do Zé Açu localiza-se a sudeste do município de Parintins, cerca de $14 \mathrm{~km}$ da sede municipal, é composto de sete comunidades rurais, segundo dados da 
Secretaria Municipal de Produção de Parintins (2013). Optou-se por fazer um recorte geográfico e selecionar três destas comunidades: Bom Socorro (distante $14 \mathrm{Km}$ da cidade de Parintins), Paraíso e Boa Esperança (distante 2,3 e 3,2 quilômetros da comunidade Bom Socorro, respectivamente) para compor o universo da pesquisa.

A referência territorial dessas comunidades está diretamente relacionada ao lago do Zé Açu, que tem sua importância tanto do ponto de vista da logística (via de acesso que interliga as comunidades com a cidade de Parintins), também como lugar do lazer e descanso, fonte de alimentos e da vida para os ribeirinhos que moram em suas margens.

Este estudo foi conduzido com base em multimétodos ou triangulação para a obtenção da máxima amplitude na descrição, explicação e compreensão do objeto de estudo, integrando métodos qualitativos e quantitativos na mesma pesquisa. Aliou-se a pesquisa etnográfica: com a descrição densa de determinadas atividades desenvolvidas pelos moradores do Zé Açu, fazendo a etnografia do modos de vida, compreendendo as atividades práticas e cotidianas dos ribeirinhos. Também foi utilizado para a coleta de alguns dados um levantamento tipo Survey.

As técnicas utilizadas foram: observação participante; entrevistas (individuais e coletivas), padronizadas, com roteiro semiestruturado e aplicação de formulários. A apresentação dos resultados é feita por meio de tabelas, quadros, mapas mentais das territorialidades rurais pesquisadas, com as representações espaciais do Zé Açu. Outras informações são apresentadas em descrições analítico-reflexivas, principalmente aquelas provindas da observação participante e entrevistas.

\section{Abordagens teóricas sobre território, territorialidades, habitus e ethos ambiental: apresentando os conceitos em questão.}

O território é uma das categorias de análise da Geografia, ele é resultante da relação da sociedade com o espaço construído e apropriado, onde os grupos sociais ocupam um espaço físico, utilizado e ampliando, estabelecendo sentimento de pertencimento e identificação.

O território é produto social constituído historicamente, tanto econômica como política e culturalmente. Tem sua construção na coletividade com caráter multidimensional, possível de engendrar múltiplas territorialidades.

O território é considerado produto histórico de mudanças e permanências ocorridas no ambiente no qual se desenvolve uma sociedade. Território significa apropriação social do ambiente; ambiente construído, com múltiplas variáveis e relações recíprocas [...] O homem age no espaço (natural e social) de se habitar, produzir e viver, objetiva e subjetivamente. (SAQUET, 2009, p. 81).

Território é um espaço utilizado pela coletividade, criando assim identidades, podendo adquirir dinâmicas econômicas próprias, em que surgem relações de poder e conflitos que visam construir formas de dominação e controle deste espaço. Como afirma Segato $(2005$, p. 2), "território alude a uma apropriação política do espaço, que tem que 
ver com sua administração e, portanto, com sua delimitação, classificação, habitação, uso, distribuição, defesa e muito especialmente, identificação".

Segundo Saquet, território é produto histórico onde há mudanças e permanências no ambiente onde se desenvolve a sociedade.

Território significa apropriação social do ambiente; ambiente construído com múltiplas variáveis e relações recíprocas. O homem age no espaço (natural e social) de seu habitat, produzir e viver, objetiva e subjetivamente. O território é um espaço natural, social, historicamente organizado e produzido; a paisagem é o nível visível e percebido deste processo. (SAQUET, 2009, p. 81).

Quando falamos de territórios também devemos falar da sociedade que o compõe, pois “[...] não serve falar de território em si mesmo, mas de território usado, de modo a incluir todos os atores [...]. A sociedade exerce permanentemente um diálogo com o território usado, e que esse diálogo inclui as coisas naturais e artificiais" (SEABRA; CARVALHO; LEITE, 2004, p. 26).

Rogério Haesbaert apresenta importante discussão sobre o conceito de território e sua compreensão nas análises espaciais, principalmente quando consideramos o estudo dos territórios simbólicos no qual "cada grupo social estaria profundamente enraizado a um 'lugar' ou uma paisagem, com a qual particularmente se identifica” (HAESBAERT, 2009, p. 118). O mesmo afirma ainda que "[...] o território é fruto de uma relação desigual de forças, envolvendo o domínio ou controle político-econômico do espaço e sua apropriação simbólica, ora conjugados e mutuamente reforçados, ora desconectados e contraditoriamente articulados" (p. 121).

Quando falamos de territórios rurais, nos referimos aos espaços que apresentam discussões sobre questões que envolvem tanto as formas de apropriação quanto o uso do território para diversos fins como a produção agrícola, pesca, pecuária, extrativismo entre outras utilizações.

Apresentamos neste estudo dentro da perspectiva da geografia cultural e da antropologia, alguns elementos que compõem o contexto sociocultural das sociedades rurais amazônicas, mais especificamente dos ribeirinhos que moram e vivem nas localidades rurais do município de Parintins e como esses aspectos estão relacionados com os seu modos de vida, pautados no trabalho, identidade, apropriação do espaço e uso dos recursos naturais.

\section{Os ribeirinhos do Zé Açu: habitus e ethos ambiental}

Um elemento a ser observado nos estudos sobre comunidade rurais, principalmente as localizadas às margens dos rios, lagos e igarapés, é o sujeito que dá vida a essa configuração territorial: os ribeirinhos.

Como afirma Fraxe, 
[...] a cultura do mundo rural de predominância ribeirinha constitui-se na expressão aceita como a mais representativa da cultura amazônica, seja quanto aos seus traços de originalidade, seja como um produto de acumulação de experiências sociais e da criatividade de seus habitantes; aquela onde podem ser percebidas, mais fortemente, as raízes indígenas e caboclas típicas de sua originalidade, florescentes ainda em nossos dias. (FRAXE, 2004, p. 302).

Faz parte da cultura dos mesmos essa imbricação com o ambiente natural, como afirmam Pantoja et al. (2006, p. 94-95): "sua cultura consegue estabelecer uma mediação que satisfazem ambas as partes [homem e natureza], tendo como resultado uma ação antrópica que pouco interfere na dinâmica ecossistêmica".

Quando falamos do modos de viver do ribeirinho estamos falando do habitus inerentes em seu cotidiano; sendo assim, deve-se ter claro o que vem a ser o habitus no contexto de vida desse grupo social. O habitus é construído social e historicamente em cada comunidade, bem como a relação do homem com o seu espaço, onde "o homem tende a se identificar conforme o que lhe foi transmitido e armazenado na memória" (RIBEIRO, 2010, p. 2).

Fraxe e Witkoski, ao analisarem a noção de habitus na obra $O$ desencantamento do mundo, de Pierre Bourdieu, explicam que:

Na concepção teórico/prática de Pierre Bourdieu, o habitus - um sistema de disposições permeado pela história social dos homens que sobrevive no mundo atual, atualizando-se igualmente nas práticas sociais - tende a perpetuar-se na vida futura. Sendo um princípio gerador de estratégias que permitem fazer frente a situações imprevisíveis e sempre renovadas, produz práticas sociais que aparecem como determinadas pelo futuro, mas que estão determinadas, em sua perspectiva, pelas primeiras experiências, pelas condições passadas de sua produção. (FRAXE; WITKOSKI, 2007, p. 135).

É importante a compreensão da noção de habitus como um sistema de disposições duráveis, estruturas estruturadas predispostas a funcionarem como estruturas estruturantes, não sendo este mera repetição de práticas acumuladas durante a vida, mas uma produção/reprodução de sistemas de ações, que são importantes e que influenciam diretamente a vida das pessoas, dando significado à mesma. Segundo Bourdieu,

[...] o habitus seria o produto do longo trabalho de inculcação e de apropriação que, mesmo que muito mais intenso e determinante durante as primeiras experiências do mundo social, prolonga-se por toda a existência dos agentes. Esse trabalho se faz necessário para que as estruturas objetivas consigam reproduzir-se, sob a forma de disposições "duráveis", em todos os organismos (individuais) duravelmente submetidos aos mesmos condicionamentos, alocados nas mesmas condições de existência. (BOURDIEU, 1979, p. 13). 
A compreensão das dimensões socioculturais dos sujeitos que dão vida e dinamicidade ao território é a questão-chave aqui apresentada. Para a discussão mais aprofundada sobre a sustentabilidade dos sistemas sociais e ambientais há de se iniciar essas reflexões tomando como base o ponto de vista dos moradores dessas comunidades rurais, investigar a fundo suas concepções de vida e de ambiente, levantar seus reais interesses, suas necessidades. Só assim poderemos compor um quadro analítico mais aproximado possível de sua realidade, e assim ajudar a pensar a Amazônia no contexto de políticas para a gestão dos territórios, que contemplem a qualidade de vida para os amazônidas, habitantes dessas áreas rurais.

Ao fazermos a abordagem sobre ethos ambiental, explicitamos que o termo ethos deriva do grego e significa "caráter ou propósito moral" de um grupo social. Quando nos referimos ao ethos, estamos falando de uma categoria mais abrangente, ou seja, designa o caráter cultural e social de um grupo ou sociedade, passa a designar uma espécie de síntese dos costumes de um povo (HONIGMANN, 1987).

Leonardo Boff também apresenta uma reflexão sobre o termo o ethos

Ethos significa os costumes, vale dizer, o conjunto de valores e de hábitos consagrados pela tradição cultural de um povo. Ethos como conjunto dos meios ordenados ao fim [bem/autorrealização] se traduz comumente por moral. Moral [mos-mores, em latim] significa, exatamente, os costumes e valores de uma determinada cultura. Como são muitos e próprios de cada cultura, tais valores e hábitos fundam várias morais. (BOFF, 2009, p. 31).

O conceito de ethos é apresentado como conjunto de costumes fundamentais, no âmbito do comportamento (instituições, afazeres, etc.) e da cultura (valores, ideias ou crenças), que são características de uma determinada coletividade, época ou mesmo região.

Para entendermos o ethos ambiental dos ribeirinhos do Zé Açu, buscamos compreender como eles apreendem o ambiente à sua volta, suas opiniões em relação à natureza, os impactos sofridos sobre ela, a atuação das instituições púbicas e como os desequilíbrios em seu ambiente natural podem afetar sua reprodução sociocultural. A partir da compreensão das questões ambientais presentes no território, também foram inferidos os possíveis caminhos e soluções para as questões ambientais apontadas pelos moradores e constatadas pelo trabalho de campo.

Acreditamos que só se pode pensar em alternativas de sustentabilidade para os territórios rurais, tanto econômica como social e cultural, a partir da realidade concreta das pessoas que lá vivem. Realidade esta composta pelas mais diversas dimensões de sua vida cotidiana onde estão imbricados e inter-relacionados o trabalho, a família, religião, festas, enfim, todo seu sistema sociocultural que dá sentido à sua existência e que compõe o seu ethos. 


\section{Território e Territorialidade no lago do Zé Açu}

Entender o habitus e o ethos das populações tradicionais e sua relação com o ambiente permitirá refletir sobre o necessário equilíbrio ambiental, condição sine qua non para a qualidade de vida que os grupos societários tradicionais têm o direito de possuir, mas que, muitas vezes, não é levado em consideração pelo sistema capitalista de produção, que busca se expandir e consolidar a qualquer preço, tanto em áreas urbanas como rurais, expondo os grupos sociais mais vulneráveis às mais diversas injustiças ambientais causadas por suas atividades.

Para fazer reflexão mais detalhada, escolhemos duas atividades tradicionais mais desenvolvidas pelos ribeirinhos do Zé Açu: a pesca e a agricultura. Não significa que não existam outras atividades como a pecuária, artesanato e o extrativismo presentes nesse território, porém, os mesmos são praticados em pequena escala.

O Zé Açu é um território já bastante alterado em sua composição florestal pelo desmatamento para criação de pastos para a pecuária, porém, essas fazendas pertencem a pecuaristas da cidade de Parintins e não dos próprios moradores que, muitas vezes, apenas trabalham como empregados nessas fazendas, cuidando e tomando conta do gado para os "patrões" que moram na cidade.

Nos concentramos na pesca e agricultura, destacando sempre a relação dessas atividades como mantenedoras da cultura e identidade. Destacamos a importância dessas atividades para manter e reforçar a identidade cultural e suas relações com o território e as territorialidades.

No entendimento da complexidade amazônica das comunidades ribeirinhas, devemos considerar a dinâmica terra, floresta e água, em que os ribeirinhos em seu trabalho e modos de vida mantêm relações diretas com a várzea e terra firme, possuindo um domínio particular do ambiente natural nas atividades desenvolvidas no roçado e lago onde exercem sua territorialidade.

No Amazonas temos mudanças e permanências nas comunidades ribeirinhas, que possuem modos de vida particular. Fauna e flora estão diretamente ligadas à vida dos ribeirinhos, que vivem à margem de rios, lagos e igarapés, onde criam sua identidade individual e coletiva. Nesses lugares, a relação homem-natureza está presente de forma mais intensa, pois os mesmos mantêm atividades cotidianas com água, terra e floresta.

\section{A agricultura e pesca no território do Zé Açu}

Para compreender e analisar as transformações ocorridas nos modos de vida e economia do Zé Açu, especificamente como essas mudanças afetam seu cotidiano, é importante apresentarmos as características do trabalho na agricultura nas áreas rurais, suas dificuldades na plantação, colheita, transporte e comercialização de seus produtos. 
Nos roçados e no lago reproduzem-se os conhecimentos repassados por gerações. Nas comunidades, tanto agricultores como pescadores realizam as duas atividades de onde tiram seu sustento, como relata o agricultor D.R.S., 40 anos.

Aqui na comunidade agente, né, tem que se acustumar com as duas atividades,
né, com agricultura e pesca, para nós sobreviver na comunidade e ter renda
no final do mês ou semana, né, eu como agricultor vejo o centro como o local
de plantação das espécies no terreno, que fica localizado na estrada, né, onde
serve para nós escoar nossa produção.
Devido eu praticar a agricultura como atividade de renda familiar, mas a
gente também pesca para comer diariamente, devido não ter muita das vezes
condições de comprar todo dia, né, então eu pratico também a pesca como
forma de consumo da família, e na comunidade, né. As pessoas têm que se
acustumar com uma vida corrida devido os lotes serem longe da casa, né, e
temos que levar nossa alimentação para o roçado. Então não podendo comprar
no comércio o frango, né, fazemos a atividade pesqueira como auxílio para a
produção agrícola, mas a renda de nós aqui na comunidade vem da agricultura,
devido ter comércio em épocas boas de venda da farinha, banana, macaxeira,
pupunha, etc. É por isso que falo que a pescaria tem ainda, mas são poucos
pessoas que vivem dessa atividade aqui no Bom Socorro do Zé Açu. (Pesquisa
de campo, 2015).

Como relata o agricultor D.R.S., as atividades de pesca e agricultura são complementares, em que os produtos oriundos dos cultivos agrícolas estão mais voltados para a geração de renda pela comercialização e a pesca voltada para o consumo da família. Ele ressalta a importância da pesca na alimentação diária, pois relata não ter condição financeira de comprar a alimentação no comércio da comunidade todos os dias da semana, ou seja, sua atividade principal de sustento da família vem da agricultura para a compra de produtos alimentícios, vestuário, remédios, etc., mas recorre à pesca para complementar a alimentação.

Essa situação é muito comum nas unidades familiares ribeirinhas na Amazônia, onde os mesmos são polivalentes, desenvolvendo várias atividades para seu sustento como a agricultura, pesca, coleta de produtos florestais, criação de gado bovino e bubalino e pequenos animais como galinhas, patos, porcos e também a caça de animais silvestres nas florestas próximas às suas casas.

A agricultura é realizada de forma tradicional, utilizando técnicas rudimentares e sem emprego de maquinário agrícola, onde a maior parte da mão de obra é familiar.

$\mathrm{Na}$ prática da pesca e da agricultura, os ribeirinhos do Zé Açu demostram grande conhecimento sobre as dinâmicas dos ecossistemas. Na agricultura, é necessário conhecimento sobre as variações do tempo, associando as estações do ano com a época do plantio. É necessário ter conhecimento sobre os tipos de solo mais propícios para o desenvolvimento das mudas de determinadas espécies.

$\mathrm{Na}$ pesca, o ribeirinho conhece bem o ciclo da vazante e enchente, os locais de pesca e o período de reprodução dos peixes. Todo esse arcabouço de conhecimentos sobre 
as variáveis naturais contribui para o sentimento de pertencimento ao território, criando assim a territorialidade no Zé Açu, sendo estabelecida uma relação de reciprocidade do homem com o ambiente natural.

A atividade agrícola praticada por quase todos os moradores do Zé Açu é para o consumo próprio e venda do excedente. A relação dos agricultores com seus lotes de produção estimula a prática dessa atividade, na qual observamos vários conhecimentos aprendidos no trabalho diário com seus pais, desde os meses de plantio até a colheita.

No processo de reprodução do modos de vida dos ribeirinhos do Zé Açu, os agricultores têm sua produção e construção material e imaterial da vida por meio dessa atividade no seu cotidiano, da qual retiram seu sustento nas unidades produtivas por intermédio das roças ou outros tipos de cultivos.

Os agricultores, em suas unidades produtivas, selecionam as espécies na medida em que o local apresenta condições de fertilidade para a plantação, sendo que a diversidade de roçados está baseada no ciclo de reposição de nutrientes do solo. O solo, depois de um tempo, perde sua fertilidade, sendo necessário o rodízio, deixando essa área que já foi plantada “descansar" por um período, sendo esta prática denominada de pousio.

A prática da agricultura no Zé Açu ocorre de forma similar a outras localidades da região Amazônica que ainda as desenvolve de forma tradicional, no que corresponde à sua organização e técnicas de cultivo (Figura 01).

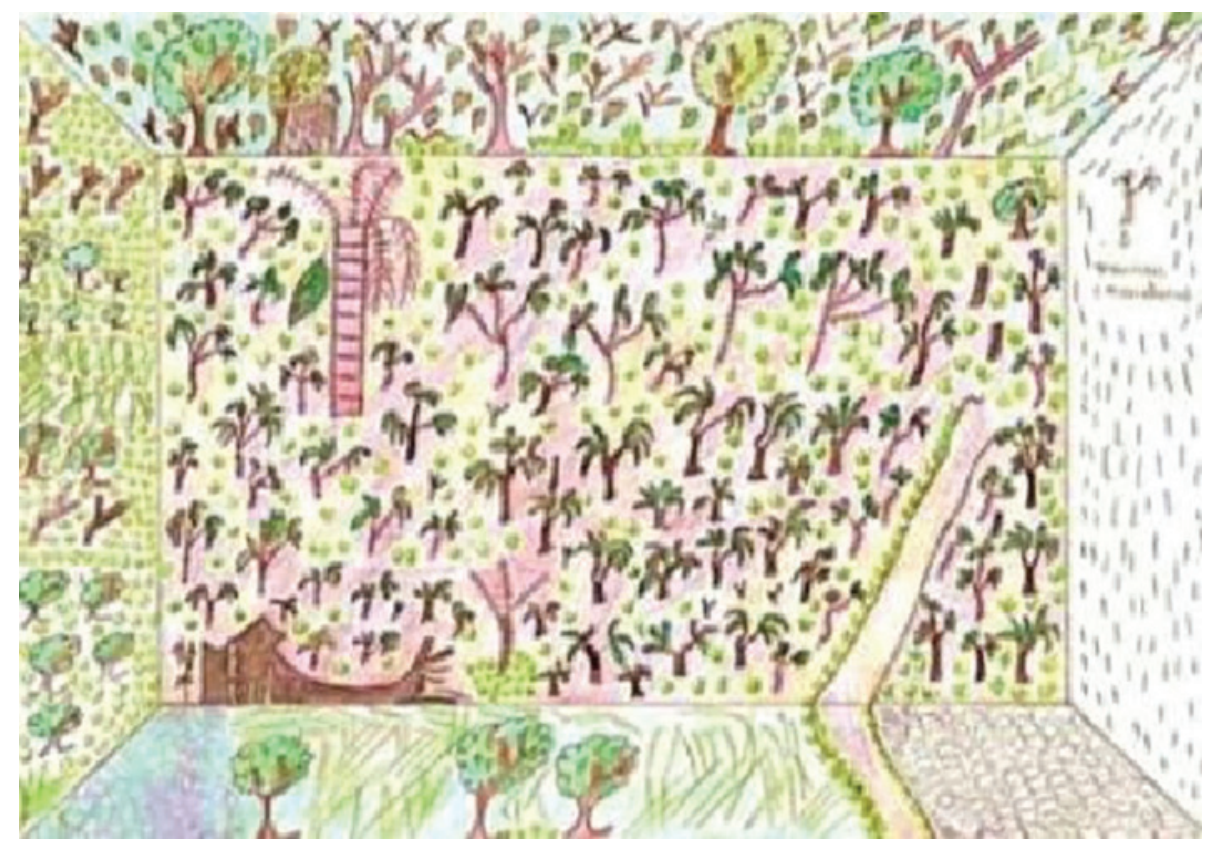

Figura 01 
Na Figura 01 está representada a plantação de mandioca, feita por um agricultor. Nesta roça são colhidas também as hortaliças que foram plantadas de forma consorciada. No caso desta família, a qual visitamos, a roça, a mesma vende o produto in natura para outras pessoas realizarem a produção da farinha e seus derivados.

O transporte dos produtos é feito por barcos de linhas ou recreios, como são chamados esses tipos de transporte e os dias de escoamento da produção na semana têm seu calendário específico, segundo os agricultores entrevistados. Na quarta-feira é o dia que a banana é escoada para a comercialização na cidade de Parintins, e na sexta-feira o produto escoado é a farinha de mandioca também para ser comercializado na sede municipal.

Noda et al. analisam essa relação entre o agricultor e o consumidor.

Os consumidores são atores sociais importantes no processo de comercialização dos produtos. Quando possível, em períodos de escassez de certos produtos, os produtores conseguem vender seus produtos diretamente para os consumidores urbanos nas áreas próximas aos mercados e feiras. A venda efetivada diretamente é mais vantajosa aos produtores, porém, mais difícil de ocorrer durante todo o ano, pois o tempo necessário de permanência no local de comercialização, provoca custos adicionais com despesas de estadia e alimentação. (NODA et al., 2007, p. 59).

$\mathrm{Na}$ assertiva de Noda et al. (2007) podemos constatar a dificuldade que os produtores rurais enfrentam, para vender diretamente seus produtos aos consumidores finais da cidade. Além de não terem apoio dos setores públicos (Estado e munícipio) na logística de transporte, eles têm gastos para permanecer por mais tempo na cidade.

Ocorrendo, principalmente, com aqueles agricultores que não têm casa de parentes ou amigos para se hospedarem durante o período de venda, obrigando-os muitas vezes a venderem seus produtos por preços muito abaixo do esperado, para que possam, assim, retornar à comunidade o mais rápido possível.

A atividade da pesca realizada no Zé Açu ocorre no lago do mesmo nome. É um dos momentos em que os moradores socializam seus conhecimentos tradicionais, onde eles ensinam seus filhos à arte da pescaria, repassando seus conhecimentos tradicionais.

A importância dessa atividade para as populações ribeirinhas amazônicas é ressaltada por Rapozo et al.:

A atividade da pesca, como um desses elementos, marca imemoravelmente a constituição histórica dos povos Amazônicos e, ao mesmo tempo, garante a construção da vida e em particular da produção e reprodução material e simbólica dos grupos sociais locais. (RAPOZO; WITKOSKI; FRAXE, 2009, p. 191).

A Figura 02 representa o mapa cognitivo, elaborados em campo com a ajuda de um pescador do Zé Açu. Nesse desenho foram identificadas as principais nascentes do lago do Zé Açu. 


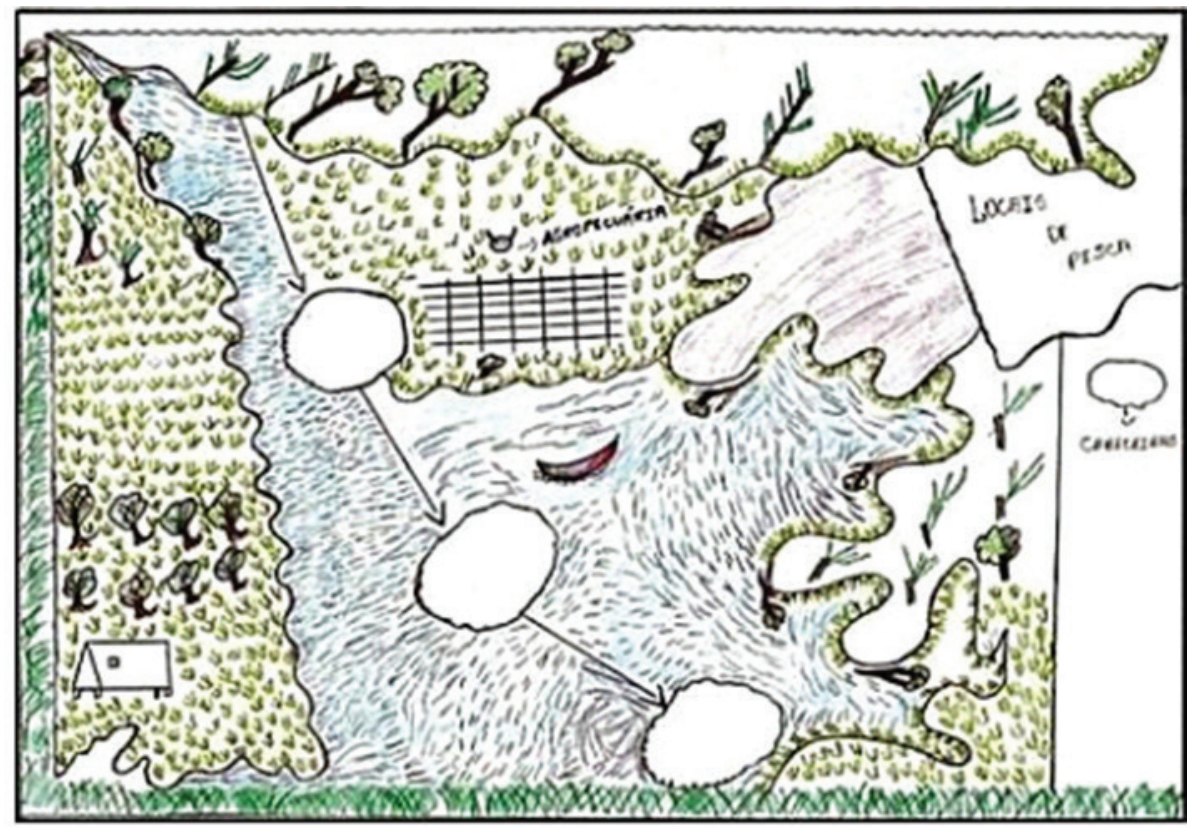

Figura 02

Essa atividade relaciona a vida diária e social das famílias e nessa relação cada movimento praticado pelos pescadores tem um significado. No acordar cedo para ir ao lago os pescadores reproduzem sua cultura, ao amolarem o anzol antes da pescaria os mesmos têm seus apetrechos renovados para mais um dia de trabalho, e ao consertarem as malhadeiras e tarrafas, principalmente aos sábados, têm a expectativa de fisgar um peixe grande no lago, que vai alimentar sua família. Ao bater na canoa espanta o pescado para longe, no casco a faca de bordo não deve faltar, e observando o banzeiro da água eles têm a percepção de cardumes grandes se aproximando. Essas atitudes dos pescadores do Zé Açu são particulares de seu cotidiano nas atividades da pesca.

O lago para os pescadores familiares é o local de captura do alimento da semana, no entanto, se a pesca for boa, tem a possibilidade de vender o excedente, como nas palavras de Castro:

Em alguns casos, a pesca é estritamente de subsistência, sendo realizada para o consumo local e distribuição do excedente para familiares vizinhos. No entanto, o pescado excedente é geralmente comercializado sempre que possível. Além disso, uma mesma família pode variar entre a pesca comercial e de subsistência ao longo do ano ou entre anos distintos. (CASTRO, 2006, p. 176).

Essa prática da pesca é realizada constantemente pelos pescadores nas épocas específicas do ano, pois na vazante os pescadores se organizam em família ou grupos de amigos para ir ao lago ou ao rio efetuarem a pescaria, sendo estimada uma grande 
quantidade de peixes e diversificação das espécies. Nessa época, alguns pescadores da comunidade vendem o excedente para seus vizinhos ou atravessadores. A prioridade é abastecer primeiramente a família para a semana, e depois, se ainda sobrar peixes no depósito, realizam a venda do excedente.

Muitos dos apetrechos dos pescadores do Zé Açu são feitos por eles mesmos, usando conhecimentos tradicionais para a fabricação desse material.

Temos a tarrafa, que é tecida pelo pescador na comunidade, e a malhadeira, que geralmente é comprada na cidade de Parintins (Figura 03 ).

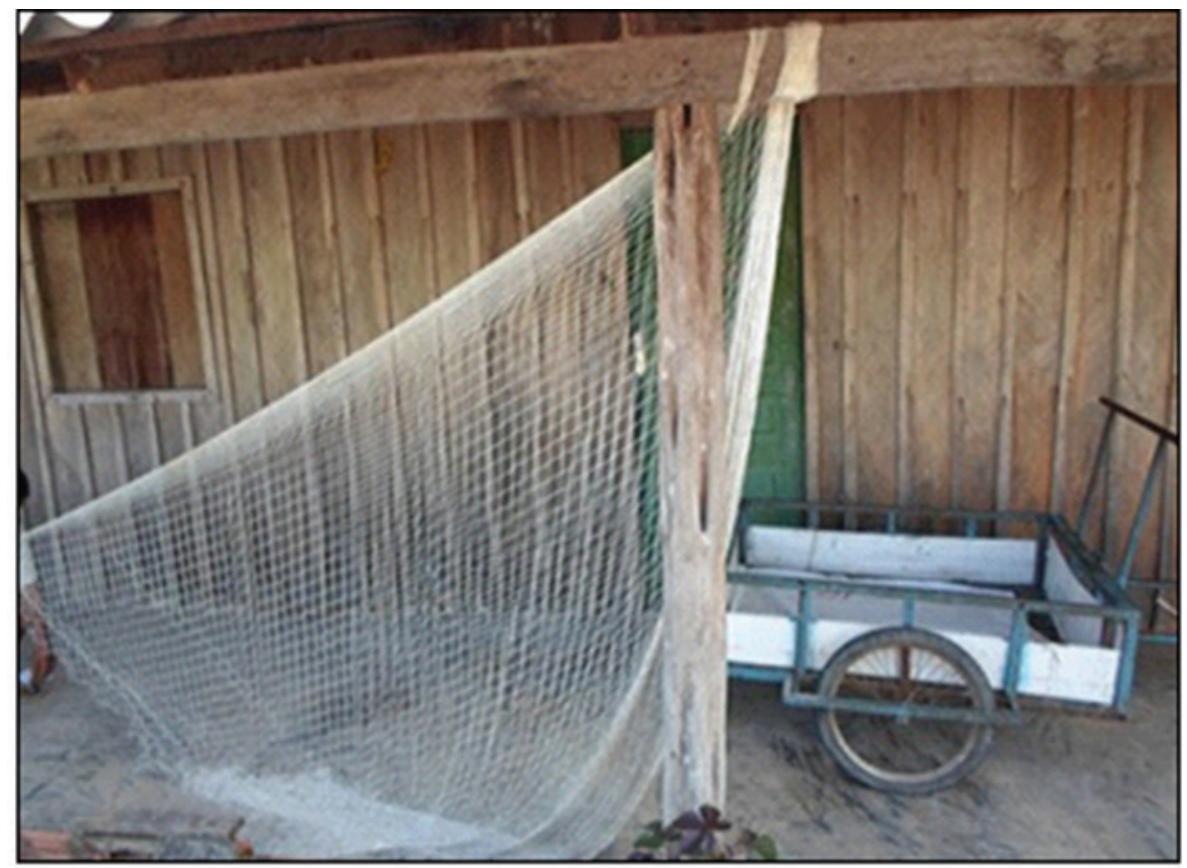

Figura 03. Fabricação da tarrafa.

Fonte: Trabalho de campo, 2015. (Foto: Charlene Muniz).

Os pescadores ribeirinhos do Zé Açu, aprendem o processo todo da pesca com seus pais, desde fazer os apetrechos, até como perceber as mudanças no lago, o som da água com o movimento dos cardumes, poderiam indicar o local certo para a captura dos peixes.

Notamos que desde criança os ribeirinhos vão adquirindo a habilidade de construir seus equipamentos de pesca e de consertá-los também, quando for necessário. $\mathrm{Na}$ Figura 04 observamos que essa arte se entrelaça com a vida e o lazer dessas crianças ribeirinhas, não tendo esse caráter de trabalho, apesar de sê-lo. 
Essas atividades fazem parte de seu mundo, um mundo em que consertar uma canoa torna-se uma brincadeira e, ao mesmo tempo, atividade necessária para deixála apta para pescar novamente. Observamos na imagem abaixo o universo de lazer e trabalho das crianças ribeirinhas, enquanto uns consertam as canoas, outras brincam nas proximidades do lago.

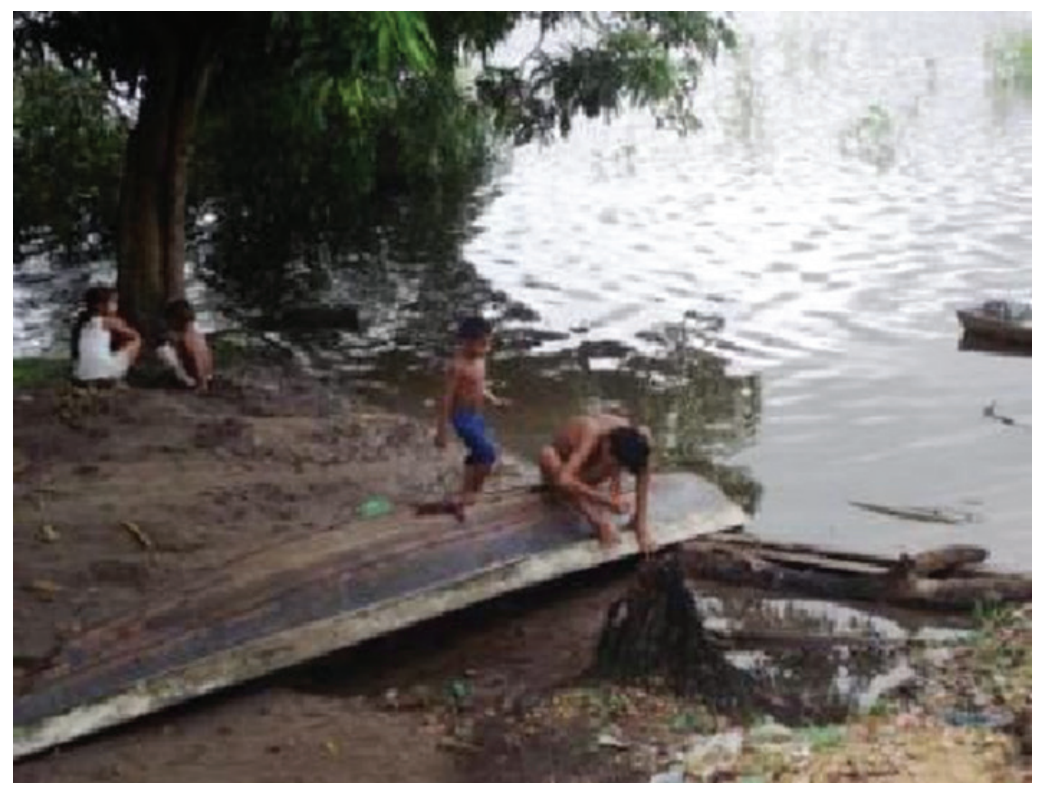

Figura 04. Menino ribeirinho consertando a canoa ás margens do lago.

Fonte: Fonte: Trabalho de campo, 2015. (Foto: Charlene Muniz).

A pescaria realizada em família e nos grupos formados pelos vizinhos próximos é de essencial importância para socialização dos conhecimentos tradicionais, e para a manutenção dessa atividade pelas futuras gerações da comunidade. Como foi destacado por Fraxe et al. (2004, p. 124), “a vivência dessas práticas durante as pescarias é muito comum nas comunidades, pois o pai atribui responsabilidades a seus filhos e ensina-os empiricamente, a identificar e demarcar os melhores pontos de pesca".

A família é base, e os filhos reproduzem esses conhecimentos, aprendem desde cedo a arte da pescaria e depois quando o pai não pode ir pescar no lago por motivos de doenças ou outras atividades relacionadas à agricultura, os filhos mais velhos desenvolvem a atividade, assumindo a responsabilidade de orientar seus irmãos para ir em busca da alimentação.

Os pescadores da comunidade mencionam também, dentre os fatores de diminuição da prática da pesca comercial, o tempo que demora em pescar uma quantidade necessária para a comercialização do excedente, pois a quantia que eles conseguem pescar 
em pouco tempo somente abastece a família, pois os mesmos precisam desenvolver outras atividades ao longo da semana.

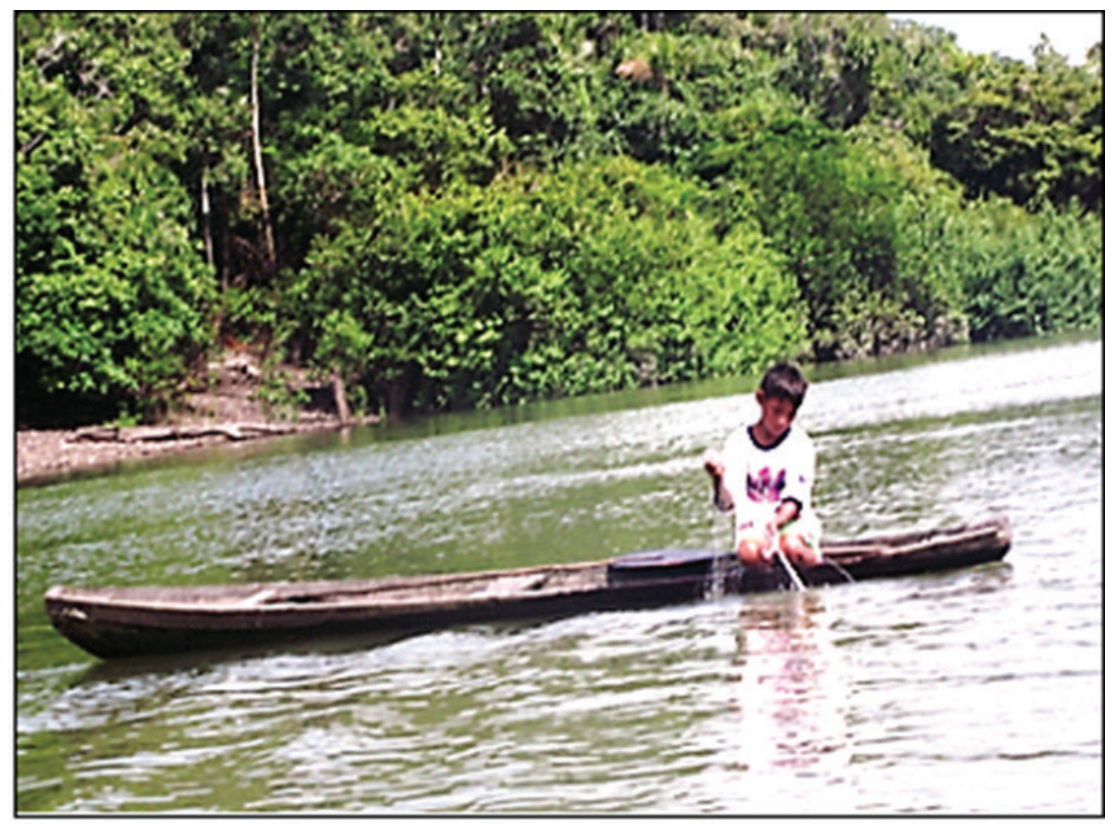

Figura 05. Menino pescando no lago do Zé Açu.

Fonte: Trabalho de campo, 2015. (Foto: Charlene Muniz).

O conhecimento socialmente construído e aprendido com as gerações passadas é fundamental para o planejamento e desenvolvimento do trabalho para obtenção da renda familiar em áreas rurais.

A área pesquisada apresenta uma economia voltada basicamente no desenvolvimento da atividade agrícola, onde a maioria da produção é vendida para a sede do município em Parintins; nas unidades de produção a força de trabalho é familiar para todo o processo diário da agricultura.

Em relação à pesca, apresenta-se principalmente para autoconsumo da família devido à dificuldade na captura de grandes quantidades necessária para o comércio na cidade, ocasionada, principalmente, pela escassez do peixe no lago.

Dentre os fatores que causaram a escassez do pescado estão as alterações na paisagem natural devido ao desflorestamento para a plantação de pastos, que acaba causando a erosão nas margens do lago, implicando em alterações físico-químicas da água e também essa remoção da vegetação ciliar, que serve de alimento para certas espécies de peixes, acaba refletindo diretamente na reprodução dos mesmos, assim como até o aumento populacional da localidade, visto que os próprios moradores falam que 
antes existia fartura tanto em peixes como outros animais como os quelônios; pássaros e outras animais para a caça, e agora com uma população de mais de mil habitantes isso já não existe mais.

Com o aumento populacional e as alterações no ecossistema local, os recursos disponíveis tanto para alimentação como para a obtenção da renda por meio da venda do excedente correspondente à pesca e à agricultura não são mais fartos como outrora.

Alguns moradores apenas praticam a pesca para complementar sua alimentação, pois em muitos casos há a preferência por comprar outros tipos de alimento como frango congelado, carne, conservas e enlatados. Isso indica que, principalmente na comunidade de Bom Socorro, vem ocorrendo uma mudança nos hábitos alimentares, ora antes baseada principalmente no peixe e na carne de animais de criação (galinhas, patos e porcos) como também na carne de caça (capivaras, tatus, aves silvestres), agora está sendo introduzido intensamente os produtos industrializados oriundos da cidade.

\section{Zé Açu: Um território em busca da sustentabilidade socioambiental}

Com base nos relatos dos moradores, na observação in loco constataram-se grandes desafios à sustentabilidade, em suas várias vertentes, para a área estudada.

Tomando como referencial um dos principais teóricos sobre esse tema, Ignacy Sachs (2009) que apresenta seis critérios que levariam à sustentabilidade dos sistemas sociais e ecológicos. Identificamos primeiramente os problemas que existem no Zé Açu, e que vão de encontro aos critérios de Sachs, e que precisam ser observados, para que o Zé Açu alcance a sua sustentabilidade.

Esses problemas que implicam na (in)sustentabilidade foram confirmados pelos resultados do grupo focal, onde utilizamos a técnica da árvore de problemas que é uma das ferramentas utilizadas pelo Diagnóstico Rural Participativo (DRP) para saber quais os principais problemas que existem em localidades rurais.

Primeiramente ouvimos essas pessoas e coletamos as suas opiniões; posteriormente organizamos para que fossem discutidos os resultados pelas próprias a fim de elaborar as alternativas.

Essa ferramenta permitiu visualizar e ajudou a entender alguns problemas, suas causas, efeitos e o que fazer para eliminá-los. O procedimento foi o seguinte: Desenhamos o tronco de uma árvore em papel pardo e o afixamos em um painel móvel; em seguida foi solicitado que os participantes escrevessem o problema priorizado em uma tarjeta e a afixassem no tronco da árvore; foi perguntado quais as causas que alimentam este problema e os seus efeitos negativos.

No tronco da árvore está visualizado o problema; as raízes simbolizam as causas do problema e os galhos, com seus frutos podres, representam os efeitos que determinado problema está gerando. 
Depois de realizada a técnica, organizamos os resultados obtidos no grupo focal. Para melhor visualização, transferimos para o computador o desenho da árvore e dispusemos as respostas dos ribeirinhos do Zé Açu sobre os problemas ambientais, suas causas e efeitos para seu ecossistema (Figura 06).
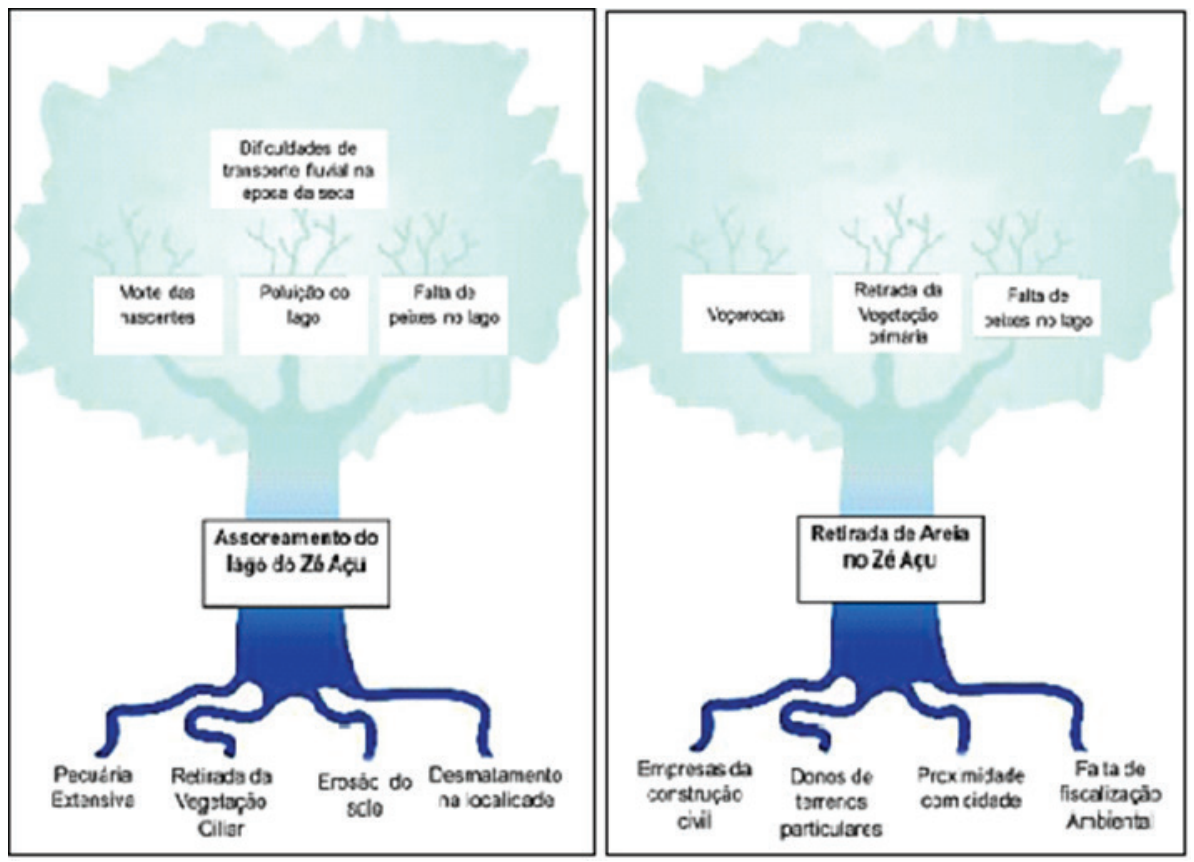

Figura 06

Com esses esquemas visualizamos as consequências dos principais problemas ambientais identificados no Zé Açu, e como afetam a vida dos ribeirinhos que moram nas margens do lago.

Com base no que foi informado pelos moradores no grupo focal, entrevistas individuais, formulários, pesquisa documental e observação direta, organizamos um quadro de possíveis caminhos para que o Zé Açu possa alcançar a sua sustentabilidade tanto ambiental, como econômica, social e cultural.

O Quadro 01 foi elaborado com as respostas, sugestões e aspirações dos moradores do Zé Açu. Ele não está completo, acreditamos que mais alternativas precisam ser inseridas. Também não significa que se fossem todas implementadas trouxessem imediatamente a sustentabilidade para esse território. 


\begin{tabular}{|c|c|}
\hline $\begin{array}{l}\text { Os critérios de } \\
\text { sustentabilidade segundo } \\
\text { Ignacy Sachs (2009) }\end{array}$ & Possíveis caminhos para a sustentabilidade no Zé Açu \\
\hline $\begin{array}{l}\text { Social } \\
\text { Alcance de um } \\
\text { patamar razoável de } \\
\text { homogeneidade social; } \\
\text { Distribuição de renda } \\
\text { justa; } \\
\text { Emprego pleno elou } \\
\text { autônomo com qualidade } \\
\text { de vida decente; } \\
\text { Igualdade de acesso aos } \\
\text { recursos e serviços sociais. }\end{array}$ & $\begin{array}{l}\text { Maior mobilização da população a fim de reivindicar, junto ao } \\
\text { poder público, melhorias nos serviços básicos; } \\
\text { Ampliação na oferta de atendimento médico, com mais recursos } \\
\text { humanos qualificados para atender nos postos de saúde nas } \\
\text { comunidades. } \\
\text { Implantação de postos de saúde em comunidades que ainda não } \\
\text { possuem. } \\
\text { Mais agentes de saúde comunitário } \\
\text { Contratação de médico que fique fixo na comunidade, } \\
\text { Mas medicamentos nos postos de saúde para distribuição gratuita } \\
\text { para os moradores } \\
\text { Transporte rápido de pacientes em caso de emergências médicas } \\
\text { (Ambulancha) } \\
\text { Ações na área da saúde preventiva, para orientação das famílias } \\
\text { quanto a prevenção de algumas doenças } \\
\text { Melhoria na qualidade da Educação, com contratação de } \\
\text { professores com qualificação, } \\
\text { Mais estrutura para a escola, com ampliação da infraestrutura para } \\
\text { atender mais alunos. } \\
\text { Salas de informática com acesso a internet } \\
\text { Implantação da Escola Familiar Rural; } \\
\text { Melhorar a infraestrutura da casa dos professores, nas } \\
\text { comunidades. E que sejam bem remunerados para que os mesmos } \\
\text { permaneçam na comunidade } \\
\text { Inclusão no orçamento municipal de recursos para investimento } \\
\text { obrigatório em projetos na área rural } \\
\text { Construção de um posto policial e manutenção de um efetivo da } \\
\text { polícia militar na comunidade; estender o programa Ronda no } \\
\text { bairro para as maiores comunidades na zona rural } \\
\text { Garantir a segurança alimentar das populações locais e que } \\
\text { venham a respeitar seus costumes e tradições } \\
\text { Construção de quadras de esporte e áreas de lazer para a recreação } \\
\text { de jovens e adultos. } \\
\text { Maior mobilização política das comunidades } \\
\text { Mais apoio dos comunitários as ações das diretorias das } \\
\text { comunidades, assim como a ajuda para ações coletivas que } \\
\text { venham a beneficiar a mesma. }\end{array}$ \\
\hline
\end{tabular}




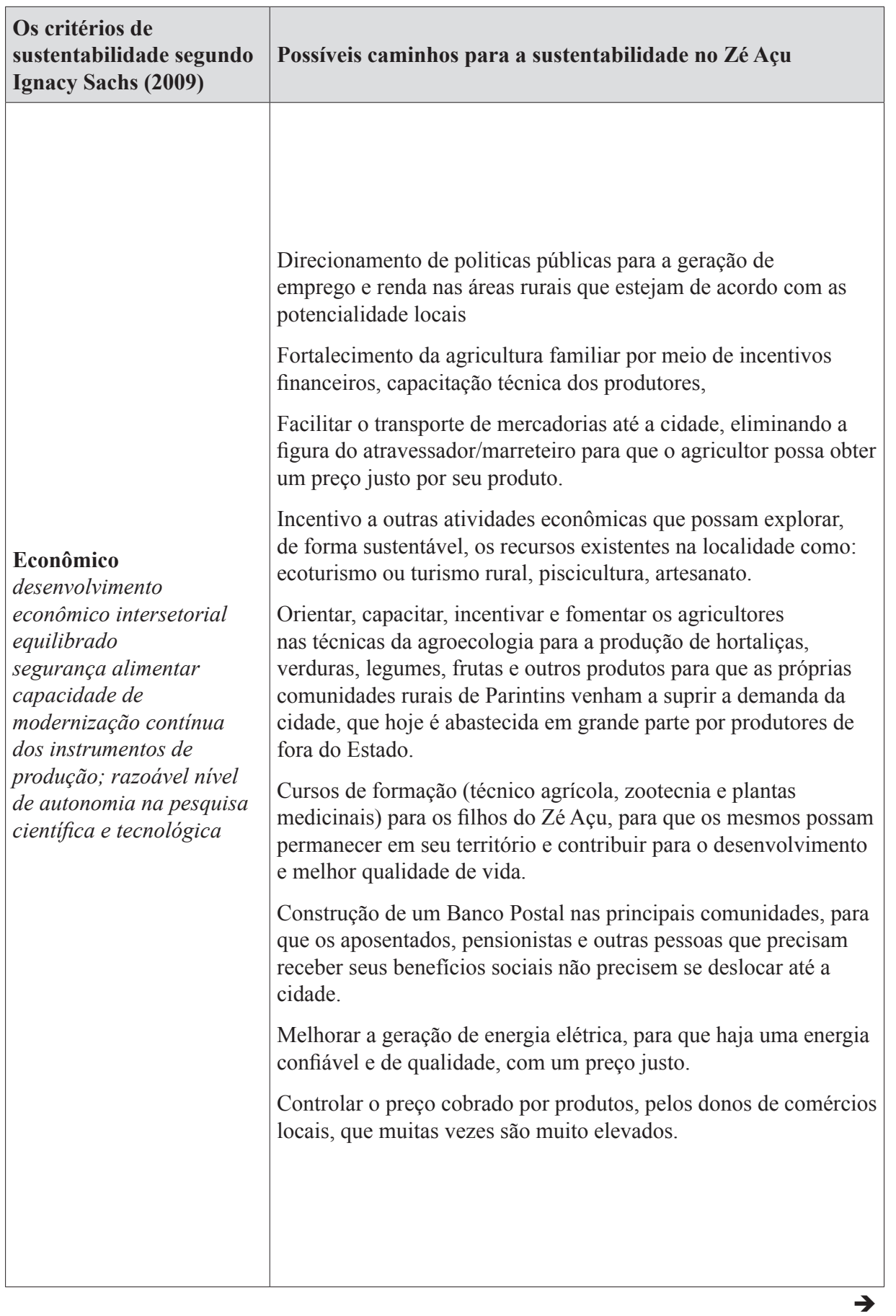




\begin{tabular}{|c|c|}
\hline $\begin{array}{l}\text { Os critérios de } \\
\text { sustentabilidade segundo } \\
\text { Ignacy Sachs (2009) }\end{array}$ & Possíveis caminhos para a sustentabilidade no Zé Açu \\
\hline $\begin{array}{l}\text { Ecológica } \\
\text { Preservação do potencial } \\
\text { do capital natural na sua } \\
\text { produção de recursos } \\
\text { renováveis } \\
\text { Limitar o uso de recursos } \\
\text { não renováveis }\end{array}$ & $\begin{array}{l}\text { Implantação da coleta seletiva nas comunidades } \\
\text { Projetos de arborização das ruas nas comunidades maiores e } \\
\text { manutenção da vegetação nas comunidades menores } \\
\text { Melhorias no abastecimento de água com o tratamento adequado } \\
\text { para consumo } \\
\text { Melhoria nas condições de saneamento básico nas comunidades } \\
\text { Fiscalização dos órgãos ambientais quanto a atividades da } \\
\text { pecuária e extração mineral no Zé Açu } \\
\text { Recuperação de áreas degradadas com o devido reflorestamento } \\
\text { das espécies nativas } \\
\text { Monitoramento das voçorocas existentes na localidade } \\
\text { Preservação da mata ciliar } \\
\text { Alternativas sustentáveis de manejo do solo (Plano de } \\
\text { Recuperação de áreas já degradadas) } \\
\text { Evitar a pesca predatória, punindo legalmente, aqueles pescadores } \\
\text { profissionais que utilizarem apetrechos proibidos por lei } \\
\text { Conservar os habitats naturais dos peixes, pássaros, quelônios e } \\
\text { pequenos mamíferos, para que os mesmos possam se reproduzir } \\
\text { sem interferências antrópicas. }\end{array}$ \\
\hline $\begin{array}{l}\text { Cultural } \\
\text { Mudanças no interior da } \\
\text { continuidade (equilibrio } \\
\text { entre o respeito à tradição } \\
\text { e inovação); } \\
\text { Capacidade de autonomia } \\
\text { para a elaboração de um } \\
\text { projeto nacional integrado } \\
\text { e endógeno (oposição às } \\
\text { cópias servis dos modelos } \\
\text { alienígenas); } \\
\text { Autoconfiança combinada } \\
\text { com abertura para o } \\
\text { mundo. }\end{array}$ & $\begin{array}{l}\text { Incentivo a manutenção dos costumes e tradições no Zé Açu } \\
\text { Revalorização do sentimento de pertencimento as suas raízes } \\
\text { rurais; } \\
\text { Valorização dos conhecimentos tradicionais oriundos da vivencia } \\
\text { e do cotidiano com o lugar } \\
\text { Incentivo a continuação da tradição de realização das festas em } \\
\text { honra aos santos seguindo seus ritos } \\
\text { Respeito as crenças religiosas e a pluralidade de credos } \\
\text { Retorno e Fortalecimento da união entre os moradores e das } \\
\text { famílias } \\
\text { Incentivo a formação de grupos de jovens na igreja } \\
\text { Fortalecimentos do clube de mulheres para a prática de atividades } \\
\text { que venham beneficiar a comunidade } \\
\text { Projetos na escola que venham a mostrar aos mais jovens a } \\
\text { importância da valorização do sentimento de pertencimento a } \\
\text { comunidade, aos habitus e costumes e as tradições da cultura local } \\
\text { Intensificação de relações intra e inter comunidades que reforcem } \\
\text { o sentimento de pertencimento ao território do Zé Açu. }\end{array}$ \\
\hline
\end{tabular}




\begin{tabular}{|c|c|}
\hline $\begin{array}{l}\text { Os critérios de } \\
\text { sustentabilidade segundo } \\
\text { Ignacy Sachs (2009) }\end{array}$ & Possíveis caminhos para a sustentabilidade no Zé Açu \\
\hline $\begin{array}{l}\text { Territorial } \\
\text { Configurações } \\
\text { urbanas e rurais } \\
\text { balanceadas(eliminação } \\
\text { das inclinações urbanas } \\
\text { nas alocações do } \\
\text { investimentos públicos) } \\
\text { Superação das } \\
\text { disparidades inter- } \\
\text { regionais } \\
\text { Estratégias de } \\
\text { desenvolvimento } \\
\text { ambiental segura para } \\
\text { áreas ecologicamente } \\
\text { frágeis (conservação } \\
\text { da biodiversidade pelo } \\
\text { ecodesenvolvimento) } \\
\end{array}$ & $\begin{array}{l}\text { Ordenamento Territorial no Zé Açu, com a definição do uso e } \\
\text { ocupação do solo, que estejam de acordo com as características } \\
\text { ambientais, econômicas e sociais daquela localidade, levando em } \\
\text { consideração as populações tradicionais ali existentes } \\
\text { Respeito as territorialidades dos ribeirinhos do Zé Açu, garantido } \\
\text { o seu acesso e uso dos recursos naturais em acordo com seu ethos } \\
\text { ambiental herdado, construído, reproduzido. Mas que também foi } \\
\text { ressignificado ao longo do tempo pelos mesmos. } \\
\text { Melhorar o acesso entre as comunidades por via terrestre (estrada) } \\
\text { e fluvial (rio) que possa facilitar o fluxo de pessoas e produtos. }\end{array}$ \\
\hline $\begin{array}{l}\text { Ambiental } \\
\text { Respeitar e realçar } \\
\text { a capacidade de } \\
\text { autodepuração dos } \\
\text { ecossistemas naturais }\end{array}$ & $\begin{array}{l}\text { Cumprimento da legislação ambiental } \\
\text { Proibição de desmatamento das áreas de proteção permanentes do } \\
\text { lago do Zé Açu. } \\
\text { Promoção de atividades de educação ambiental como palestras } \\
\text { sobre as temáticas: Sustentabilidade e Desenvolvimento } \\
\text { Sustentável; Turismo e meio ambiente; Paisagens Naturais e } \\
\text { Culturais; Ecossistemas Lacustres; a Importância da àgua no } \\
\text { Século XXI; Legislação Ambiental, Degradação Ambiental, } \\
\text { Coleta seletiva, entre outros temas. } \\
\text { Capacitar os comunitários em monitoramento ambiental para que } \\
\text { os mesmos possam fiscalizar e denunciar as injustiças ambientais } \\
\text { cometidas no Zé Açu. } \\
\text { Não distribuição de lotes, para assentados que não cumprirem o } \\
\text { perfil necessário para ocupar esses lotes } \\
\text { Mais fiscalização do INCRA sobre as atividades incoerentes com } \\
\text { um projeto de assentamento rural } \\
\text { Realização de oficinas para sensibilização e reaproveitamento de } \\
\text { partes de resíduos sólidos } \\
\text { Programas de incentivo a criação/manutenção de hortas nos } \\
\text { quintais das casas } \\
\text { Incentivar a criação e manutenção de uma Horta comunitária } \\
\text { Incentivo a criação/manutenção das farmácias naturais nos } \\
\text { quintais, pela plantação e uso das ervas medicinais } \\
\text { Incentivo a criação/manutenção dos jardins, com suas plantas } \\
\text { ornamentais na frente e nos quintais das casas } \\
\text { Programas e projetos que venham a demostrar a importância dos } \\
\text { quintais agroflorestais para a alimentação e venda do excedente }\end{array}$ \\
\hline
\end{tabular}


Trata-se mais de uma tentativa de reflexão sobre as alternativas disponíveis para a possível melhoria na qualidade de vida dessas pessoas que moram, trabalham e vivem nessas áreas rurais e que merecem viver com tranquilidade e com o ambiente saudável, para que se reproduzam socialmente, mantendo as suas tradições, seus modos de vida, que não é melhor ou pior que de outras sociedades, mas é a manifestação própria e seu ethos ambiental, que precisa ser respeitado e mantido.

Lembramos do conceito de "decrescimento" (LATOUCHE, 2012), que se trata da tentativa de pensar o crescimento não da forma como o sistema econômico vigente pensa, ou seja, em termos numéricos. É pensar que o desenvolvimento pode se dar de várias formas, que não necessariamente pode ser em termos financeiros, ou de aumento na exploração de recursos naturais. Por isso, nosso cuidado ao apresentar essas alternativas, e que as mesmas devem ser bem avaliadas para saber até que ponto elas de fato trariam bem-estar e qualidade de vida a essa população sem alterar de forma significativa seu habitus e seu ethos ambiental.

\section{Considerações Finais}

Em virtude dos dados apresentados e dos resultados inferidos no trabalho, que teve como objetivo principal compreender as territorialidades rurais em Zé Açu, no município de Parintins, e a sua relação com a sustentabilidade socioambiental, identificamos como os ribeirinhos do Zé Açu estabelecem as suas territorialidades, usam e se apropriam desse território. Levando em consideração esses aspectos, os mesmos estabelecem uma relação com seu ambiente que é mediada pela cultura que orienta seu ethos ambiental.

Para compreendermos essa complexa relação foi necessário analisar o habitus e o ethos ambiental dos ribeirinhos do Zé Açu. Compreender os aspectos sociais, ambientais e culturais do Zé Açu, sob o ponto de vista de território, e entender as territorialidades dos sujeitos sociais que nele vivem foi o principal desafio desta pesquisa, pois a perspectiva do território, assim como do lugar, abre um campo abrangente que permite interligar sociedade, ambiente e cultura. Analisamos esses elementos como componentes importantes para a compreensão da sustentabilidade nas suas dimensões: econômica, social, ambiental e cultural.

Buscamos demonstrar que sociedade, ambiente e cultura são interdependentes e estão intimamente interconectados, se relacionam e se transformam mutuamente. Alterações em um causam transformações no outro. Portanto, é necessário buscar o equilíbrio entre a sociedade e o ambiente, sendo essa condição sine qua non para se alcançar a sustentabilidade.

Território este que traz em seu interior as territorialidades manifestas na forma de apropriação de seus moradores, os ribeirinhos do Zé Açu, no tocante a seus recursos ambientais: águas, terras e floresta, mas que são também fonte de seu capital cultural. 
No caso do território estudado, as atividades da pesca e da agricultura que, além de serem atividades que ajudam a manter o corpo (pois é por meio destas que as famílias se alimentam com a farinha de mandioca e da macaxeira, o beijú; e os mais variados peixes), também ajudam a alimentar a sua essência, o ethos ambiental ribeirinho. São atividades mantenedoras da cultura e da identidade, ou seja, seu vínculo com e no território. São as expressões mais claras da territorialidade dessas pessoas.

Por essas atividades serem importantes não só do ponto de vista econômico e cultural, e pelas mesmas já estarem demostrando certo enfraquecimento no Zé Açu é que consideramos necessário um olhar mais cuidadoso, não só do poder público municipal ou estadual, mas também das instituições de pesquisa e universidades, para que possam encontrar alternativas para as problemáticas e para proporcionar melhoria na qualidade de vida dessas comunidades do Zé Açu.

A compreensão da relação do território com a cultura pode auxiliar nas análises sobre as estratégias utilizadas por esses grupos para ordenar e controlar melhor seus territórios, assim como na conservação dos recursos naturais de forma a garantir o equilíbrio entre os ecossistemas e os sujeitos que os utilizam, pois esse é o pressuposto básico da sustentabilidade em sua dimensão social, econômica, cultural e ambiental.

Portanto, este estudo abordou a importância de pensar o território e as territorialidades do ponto de vista da sustentabilidade. A relação direta existente entre o habitus e o ethos ambiental dos grupos societários tradicionais e a forma como organizam os espaços.

A reflexão sobre a sustentabilidade deve contemplar as dinâmicas sociais, econômicas, culturais e ambientais como um todo. Essas questões estão presentes na vida dos povos de comunidades tradicionais, e têm reflexo direto na forma de apropriação e uso de seus territórios. Por isso, a importância de conhecer e respeitar o habitus e ethos ambiental dos ribeirinhos do Zé Açu, destaque nesta pesquisa. Para que seu território seja mantido e legitimado, possibilitando a continuidade da (re)produção de seu modos vida.

\section{Referências}

BOURDIEU, Pierre. O desencantamento do Mundo: estruturas econômicas e estruturas temporais. São Paulo: Editora Perspectiva, 1979.

BOFF, Leonardo. Ethos Mundial: um consenso mínimo entre os humanos. Rio de Janeiro: Record, 2009.

CASTRO, Fábio de. Economia familiar cabocla na várzea do médio-baixo Amazonas. In: ADAMS, Cristina; MURRIETA, Rui; NEVES, Walter (Org.). Sociedades Caboclas Amazônicas: modernidade e invisibilidade. São Paulo: Annablume, 2006.

FRAXE, Therezinha de Jesus Pinto. Cultura cabocla-ribeirinha: mitos, lendas e transculturalidade. São Paulo: Annablume, 2004. 
FRAXE, Therezinha; WITKOSKI, Antônio Carlos. A noção de habitus em $O$ desencantamento do mundo. Rev. Somanlu, Manaus, ano 7, n.1, jan./jun. 2007.

HAESBAERT, Rogério. Territórios alternativos. 2. ed. São Paulo: Contexto, 2009.

HONIGMANN, J. J. Ethos. In: . Dicionário de Ciências Sociais. 2. ed. Rio de Janeiro: FGV, 1987.

LATOUCHE, Serge. O decrescimento. Por que e como? In: LÉNA, Philipe; NASCIMENTO, Elimar Pinheiro do (Org.). Enfrentando os limites do crescimento: sustentabilidade, decrescimento e prosperidade. Rio de Janeiro: Garamond, 2012.

NODA, Sandra do Nascimento (Org.). Agricultura Familiar na Amazônia das águas. Manaus: EDUA, 2007.

PANTOJA, Geandro Guerreiro; FRAXE, Therezinha de Jesus Pinto; WITKOSKI, Antônio Carlos. Vidas molhadas - Um estudo socioambiental de comunidades ribeirinhas da várzea amazônica. In: Rev. Somanlu, Manaus, ano 6, n.1, jan./jun. 2006.

RAPOZO, Pedro; WITKOSKI, Antônio Carlos; FRAXE, Therezinha de Jesus Pinto. Pescadores e territórios sociais no mundo do trabalho da pesca na Costa do Pesqueiro II Baixo rio Solimões -Manacapuro. In: FRAXE, Therezinha; WITKOSKI, Antônio Carlos; SILVA, Susy Cristina Pedroza da. A pesca na Amazônia Central: ecologia, conhecimento tradicional e forma de manejo. Manaus: EDUA, 2009.

RIBEIRO, Marcela Arantes. Entre o rio e a mata: História oral e espaço Vivido em Comunidades Ribeirinhas. In: Anais do X Encontro Nacional de História Oral. Recife: UFPE, 2010.CD-ROM.

SACHS, Ignacy. Caminhos para o desenvolvimento sustentável. 3. ed. Rio de Janeiro: Garamond, 2009.

SAQUET, Marcos Aurélio; SPOSITO, Eliseu Savério. Territórios e Territorialidades: teorias, processos e conflitos. São Paulo: Expressão Popular, 2009.

SEABRA, Odette; CARVALHO, Monica de; LEITE, José Correa. Território e Sociedade: entrevista com Milton Santos. Editora Fundação Perseu Abramo, São Paulo, 2004.

SEGATO, Rita Laura. Em busca de um léxico para teorizar a experiência territorial contemporânea. Série Antropológica. Brasília: 2005. 
Charlene Maria Muniz da Silva

Doutora em Ciências do Ambiente e Sustentabilidade na Amazônia. Possui mestrado em Geografia pela Universidade Federal do Amazonas. Atualmente é professora adjunta do curso de Licenciatura Plena em Geografia da Universidade do Estado do Amazonas.

UEA/ Centro de Estudos Superiores de Parintins. Estrada Odovaldo Nôvo Djard de Vieira, 69150-000 - Parintins, AM - Brasil.

E-mail: charlenemds@yahoo.com.br

Therezinha de Jesus Pinto Fraxe

Possui graduação em Agronomia pela Universidade Federal do Amazonas, Mestrado em Sociologia pela Universidade Federal do Ceará e Doutorado em Sociologia pela Universidade Federal do Ceará. Atualmente é professor Associado da Universidade Federal do Amazonas e coordenado do Programa de Pós-Graduação Ciências do Ambiente e Sustentabilidade na Amazônia.

UFAM, Faculdade de Ciências Agrárias, Departamento de Ciências Fundamentais e Desenvolvimento Agrícola. Av. Gal. Rodrigo Otávio Jordão Ramos, 3000

Aleixo 60077-000 - Manaus, AM - Brasil

Ee-mail: tecafraxe@uol.com.br

Recebido para publicação em junho de 2015 Aprovado para publicação em janeiro de 2016 